\title{
Conservative Management of Splenic Trauma
}

Maj RA Daoud

FRCS (Eng), FRCS (Glas), FRCS (Gen), RAMC

Specialist Registrar in General Surgery

Mr AK Taghizadeh

FRCS

SHO in General Surgery

Dr RB Pickford

FRCR

Consultant Radiologist

Mr DRB Jones

$\mathrm{McH}, \mathrm{FRCS}$

Consultant General Surgeon

Departments of General Surgery and Radiology, Nevill Hall Hospital, Abergavenny

Summary: Since the 1970's an increasingly conservative approach to splenic trauma has been practised in many countries. Haemodynamically stable patients who have been carefully assessed clinically and radiographically may safely be treated non-operatively. In those patients who require surgery the spleen may be preserved by splenorrhaphy or partial splenectomy. This approach has been practised at our hospital and we present our experience over seven years to show that expectant treatment of splenic injury following trauma is safe.

\section{Introduction}

Kocher in 1911 stated that injuries of the spleen should be treated by excision of the gland: "No evil effects follow its removal, while the haemorrhage is effectively stopped". It is now recognised that the spleen has an important immunological and haematological role; its removal carries a number of sequelae, the most important of which is overwhelming post splenectomy sepsis (1). In selected patients with splenic injury careful assessment, combined with non-invasive imaging, good resuscitation and close monitoring will avoid the need for splenectomy. A policy of splenic conservation has been followed in our hospital since 1990. The result of seven years of experience with this method of treatment is presented here.

Patient and Methods

Between 1990 and 1997, seventeen patients with traumatic splenic injury were treated at our hospital. The injuries were for the most part a result of blunt impact from domestic or road traffic accidents. The patients were managed by the General Surgical team in a 430 bed district general hospital. Patients were assessed according to the Advanced Trauma Life Support guide lines. If an intra-abdominal injury was suspected an ultrasound examination was performed by a consultant radiologist. An abdominal CT scan was not considered necessary in any of our patients.

Patients with isolated splenic injury, and no other significant intra or extra abdominal injury were treated non-operatively. They were resuscitated, and then carefully monitored in a high dependency unit. Haematocrit was checked daily. The abdominal ultrasound was repeated at two weeks and again as an outpatient at three months. Patients were advised to avoid vigorous physical activity and contact sports for a period of three months following their injury. They received pneumococcal and Haemophilus Influenza type B vaccinations, and long term prophylactic penicillin.
Patients with splenic injury who were thought to require operative intervention were those who:

Had suspected additional intra-abdominal injuries

Significant extra abdominal injuries

Continued haemodynamic instability despite adequate resuscitation as shown by a persistent tachycardia of more than 100/minute or blood transfusion of more than six units

Evidence of deterioration whilst on conservative treatment

A retrospective study was made of the patients' case notes. The details which were recorded were: age, sex, medication, pulse and blood pressure and the number of units of blood transfused, operative details and follow up.

\section{Results}

Between 1990 and 1997 a total of seventeen patients with splenic injury were seen.

Nine patients were treated non-operatively with a good result (Table 1). One patient was initially treated non-operatively but required a late operation: he was a 15 year old male who was involved in a motorbike accident, on the fifth day post injury developed a tachycardia of $110 / \mathrm{min}$ and generalised abdominal tenderness and therefore underwent laparotomy and splenectomy. This was the only patient in the non-operatively treated group who had been involved in a road traffic accident. Two patients who were successfully treated in the non-operative group were above 80 years old and were taking warfarin. The mean blood number of units of blood that this group received was 1.5 .

Eight patients underwent operative treatment, seven undergoing splenectomy (Table 2). Of these, three were involved in road traffic accidents. One patient had additional liver and pancreatic injuries and died three weeks postoperatively. Two patients who suffered relatively minor damage to the spleen but were taking both beta blockers and 
Table 1

Patients Treated Non-Operatively for Splenic Injuries

\begin{tabular}{|c|c|l|c|c|c|c|}
\hline Age & Sex & Type of Trauma & Medication & Pulse & $\begin{array}{c}\text { Mean Arterial } \\
\text { BP }\end{array}$ & $\begin{array}{c}\text { Number of Blood Units } \\
\text { Transfused }\end{array}$ \\
\hline 5 & Male & Fell while playing & -- & $12 / \mathrm{min}$ & $99 \mathrm{mmHg}$ & 1 \\
\hline 7 & Female & Fell against bath edge & -- & $110 / \mathrm{min}$ & $100 \mathrm{mmHg}$ & - \\
\hline 11 & Male & Fell from a tree & -- & $100 / \mathrm{min}$ & $96.6 \mathrm{mmHg}$ & 1 \\
\hline 13 & Male & Punched in abdomen & -- & $92 / \mathrm{min}$ & $96.6 \mathrm{mmHg}$ & \\
\hline 16 & Female & $\begin{array}{l}\text { No definite trauma } \\
\text { (Infectious Mononucleosis) }\end{array}$ & -- & $120 / \mathrm{min}$ & $96.6 \mathrm{mmHg}$ & \\
\hline 42 & Male & Hit by iron bar & -- & $70 / \mathrm{min}$ & $93.3 \mathrm{mmHg}$ & - \\
\hline 50 & Male & Kicked by a cow & -- & $70 / \mathrm{min}$ & $96.6 \mathrm{mmHg}$ & -- \\
\hline 85 & Female & Fell over & Warfarin (INR 1.9) & $76 / \mathrm{min}$ & $100 \mathrm{mmHg}$ & - \\
\hline 88 & Female & Fell against a chair & Warfarin (INR 2) & $68 / \mathrm{min}$ & $103.6 \mathrm{mmHg}$ & 4 \\
\hline
\end{tabular}

Table 2

Patients Treated by Splenectomy

\begin{tabular}{|c|c|l|c|c|c|c|}
\hline Age & Sex & Type of Trauma & Medication & Pulse & $\begin{array}{c}\text { Mean Arterial } \\
\text { BP }\end{array}$ & $\begin{array}{c}\text { Number of Blood Units } \\
\text { Transfused }\end{array}$ \\
\hline 9 & Female & Punched in abdomen & -- & $160 / \mathrm{min}$ & $86.6 \mathrm{mmHg}$ & 6 \\
\hline 15 & Male & Motorbike accident & -- & $110 / \mathrm{min}$ & $96.6 \mathrm{mmHg}$ & 6 \\
\hline 28 & Male & $\begin{array}{l}\text { Road traffic accident: } \\
\text { Left rib fracture; left haemothorax: } \\
\text { penetrating injury of diaphragm } \\
\text { and spleen; fracture right femur. }\end{array}$ & -- & $144 / \mathrm{min}$ & $103.3 \mathrm{mmHg}$ & 4 \\
\hline 54 & Female & $\begin{array}{l}\text { Road traffic accident: } \\
\text { Liver \& pancreatic injury. }\end{array}$ & -- & $102 / \mathrm{min}$ & $101.3 \mathrm{mmHg}$ & 30 \\
\hline 57 & Female & Fell over & $\begin{array}{c}\text { Warfarin (INR 4) } \\
\text { Beta-Blocker }\end{array}$ & $64 / \mathrm{min}$ & $91.6 \mathrm{mmHg}$ & 14 \\
\hline 61 & Male & $\begin{array}{l}\text { Fell over a ladder one week } \\
\text { prior to admission }\end{array}$ & -- & $96 / \mathrm{min}$ & $90 \mathrm{mmHg}$ & 8 \\
\hline 67 & Male & Fell from bed & $\begin{array}{c}\text { Warfarin (INR 2.8) } \\
\text { Beta-Blocker }\end{array}$ & $75 / \mathrm{min}$ & $93 \mathrm{mmHg}$ & \\
\hline
\end{tabular}

warfarin became haemodynamically unstable and underwent splenectomy. The mean number of blood units that the operated patients received was 10.8 .

In one patient who underwent operative treatment the spleen was conserved. He was injured following a push bike accident, found to have a splenic tear and treated by packing the tear with surgicel. He made an uneventful recovery.

\section{Discussion}

Splenectomy has been the mainstay treatment for splenic injury. The complications of splenectomy have however been becoming increasingly apparent. King and Schumacker reported increased susceptibility to infection following splenectomy to treat spherocytosis (2). Overwhelming post-splenectomy infection is well recognised (3) and the incidence has been reported to be as high as $50 \%$ in children (4). Prophylactic vaccination and antibiotics do not guarantee protection from fatality (5).

A change in approach to paediatric splenic injury started in the late 1960 's based on a number of observations. The chance finding at autopsy of a completely transected yet healed spleen in a child who was thought to have injured his spleen some time previously implied that major splenic injury could be well tolerated (6). Delayed splenic rupture is almost unknown in children, and because of its position the spleen is often the only

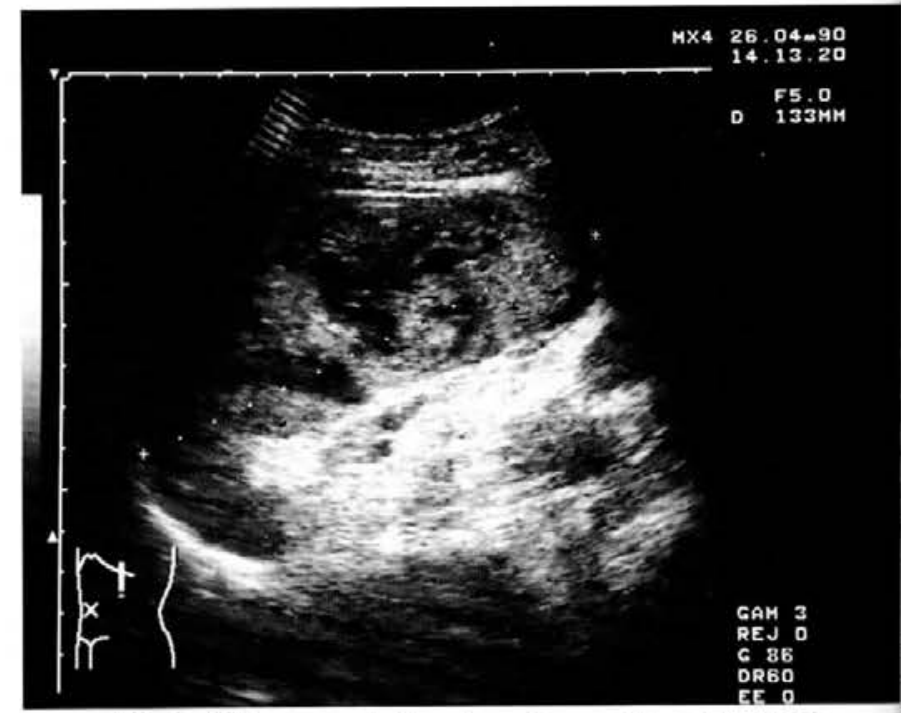

Fig 1. Ultrasound showing disruption of splenic architecture.

visceral organ damaged by trauma in children. It is for thes reasons that paediatric surgeons became the first to adopt a mon conservative approach to splenic injury (7). In the USA in th 
JU

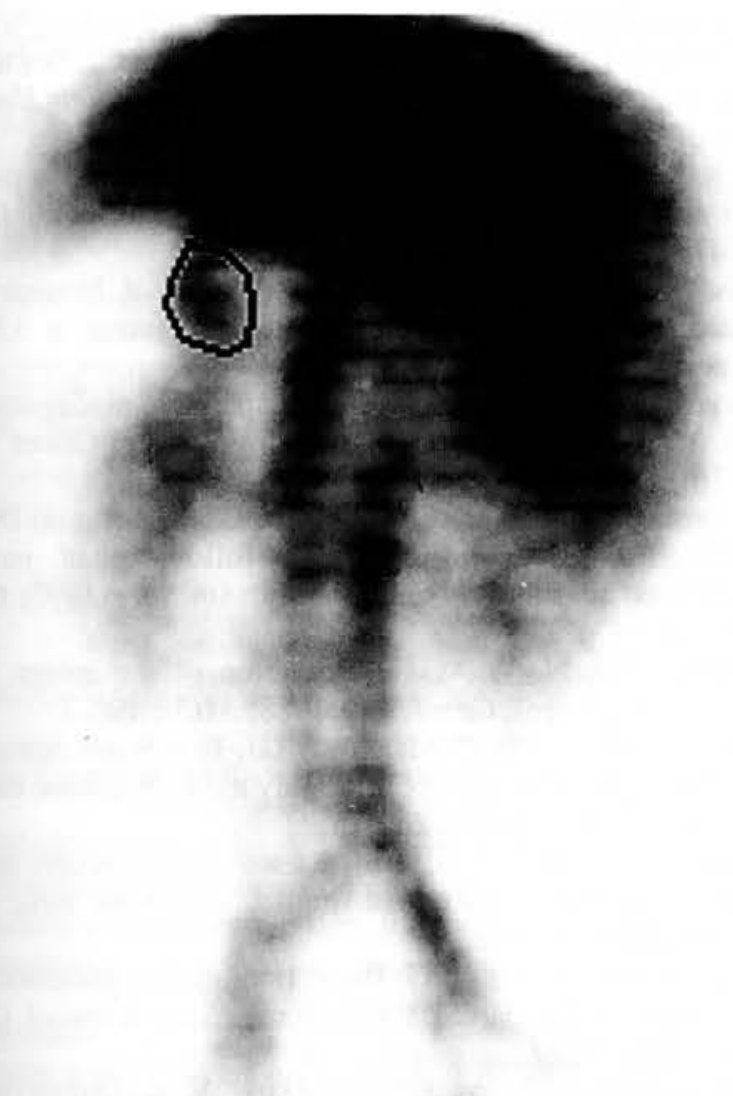

Fig 2. Isotope scan showing functional splenic tissue after partial splenectomy. (R A Daoud).

decade following 1965 , splenectomy was the standard treatment of splenic injury; by the decade preceding $1985,62 \%$ of injured spleens were treated conservatively, and of those that did require operation, a splenic salvage rate of $85 \%$ was achieved (8). This approach in management of splenic trauma has become more widely adopted in adults as well as children $(9,10,11)$. Rates of successful non-operative management of splenic injury of between $60 \%$ and $97 \%$ have been reported $(11,12,13,14,15)$.

One of the reasons that the conservative approach to management of splenic injury has begun to gain such wide acceptance is the improved access to good radiological imaging. Ultrasound can be an accurate means of assessing splenic injury, and can be performed in the emergency treatment room. Computerised Tomography and Magnetic Resonance Imaging will provide very detailed imaging but their value is limited by time taken to transfer patients and to perform imaging. Ultrasound success in detecting splenic injury is dependent on the nature of the injury: superficial tears may be difficult to detect but their presence is suggested by a localised collection of blood; extensive lacerations, intrasplenic and sub capsular haematomas are readily shown by the presence of gross architectural disruption (Fig 1). In obese individuals who may have high diaphragms, careful examination is required to avoid missing haemotomas which have similar echogenicity to splenic tissue. The presence of free fluid signifying blood is suggestive of but not diagnostic for solid organ injury, as it can arise from mesenteric injury either in isolation or in combination with other visceral injuries. In major trauma centres in the USA ultrasound has proven invaluable in providing quick, accurate, non invasive diagnostic information, which can easily be integrated into resuscitation and has supplanted peritoneal lavage and CT scanning (16). In one study involving 1000 patients it was found to have a diagnostic accuracy of $97 \%$ with a sensitivity of $88 \%$ and a specificity of $99 \%$ (17).
The conservative approach may be extended to the pathological spleen (18), as our experience with a patient with infective mononucleosis demonstrates. Patients with haemophilia and splenic injury may be treated non-operatively (19). Slowed coagulation is not a bar to conservative treatment; two of our patients who were taking warfarin were safely managed non-operatively. However a combination of beta blockade and anti coagulation was deemed to be best managed by splenectomy.

An argument against conservative management of splenic injury is the perceived risk of increased likelihood of blood transfusion and its attendant long term sequelae. Patients who come to require surgery after a period of expectant treatment on average receive double the number of units of blood as those who underwent primary surgical treatment (20). This concern has not been born out by our series; those undergoing surgery on average received six times as many units of blood as those treated non surgically. In the non-operative group $44 \%$ of patients received no transfusion at all. This probably reflects differences in the nature of the injuries between the two groups, those requiring surgery having more extensive injuries to begin with. In any case patients who undergo any form of surgery will develop complications and require more blood transfusion than those treated non surgically (21).

Repair of the injured spleen is a technique with considerable success in experienced hands (22). We were able to apply salvage in only one of our patients. An alternative to splenorrhaphy is sub total splenectomy preserving the upper pole vascularised only by the short gastric vessels (23) (Fig 2). A human fibrin seal has been used experimentally in rabbits (24). Absorbable mesh repair has been described to help achieve a splenic salvage rate of $67 \%$ (25). Laparoscopy has been used as both a diagnostic and therapeutic tool, and can be used to apply a fibrin glue (26).

The role of autotransplantation of splenic tissues has been questioned (27). The lack of success may be due to the absence of the type of blood supply that the normal spleen receives, which may be important in clearing pathogenic organisms. A high proportion of transplants, $17.5 \%$ will undergo aseptic necrosis and even small bowel obstruction has been reported (28).

The results of our study concord with the previous findings that on isolated splenic injury may be treated non surgically, with close clinical and radiological monitoring. This approach is safe in patients with isolated splenic injury, sustained by low velocity, low energy accidents. Patients who have not been involved in road traffic accidents (29), and who become readily haemodynamically stable after initial fluid resuscitation, whose symptoms progressively improve after the injury are most likely to benefit from this approach. Patients who need to undergo prolonged anaesthesia for treatment of extra abdominal injuries or whose level of consciousness needs monitoring are unsuited to this approach (30).

\section{REFERENCES}

1. Shaw JHF, Print CG. Post splenectomy sepsis. Br J Surg 1989; 76: 1074-81

2. King H, SChumacker H. Splenic studies: Susceptibility to infection after splenectomy performed in infancy. Am Surg 1953; 136: 239-41.

3. Chaikof EL, MCCABE CJ. Fatal overwhelming postsplenectomy infection. Am J Surg 1985; 149: 534-9.

4. ElLISON EC, FABRI PJ. Complications of splenectomy, etiology, prevention, and management. Surg Clin North Am 1983; 63: 1313-30.

5. Evans D. Fatal postplenectomy sepsis despite prophylaxis 
with penicillin and pneumococcal vaccine. Lancet 1984; i: 1124.

6. Upadhyaya P, Simpson JS. Splenic trauma in children. Surg Gynecol Obstet 1968; 126(4): 781-90.

7. Irving M, Atrwood S, Gough D. Splenectomy, Partial Splenectomy and laparoscopic Splenectomy. D Carter, CG Russell. Rob \& Smith's Operative Surgery. 5th ed. London: Chapman and Hall Medical, 1996: 236.

8. Lally KP, Rosario V, Mahour GH, Woolley MM. Evolution in the management of splenic injury in children. Surg Gynecol Obstet 1990; 170(3): 245-8.

9. Morrell DG, Chang FC, Helmer SD. Changing trends in the management of splenic injury. Am J Surg 1995; 170(6): 686-90.

10. Clancy TV, Ramshaw DG, Maxwell JG, et al. Management outcomes in splenic injury: a statewide trauma centre review. Ann Surg 1997; 226(1): 17-24.

11. Villalba MR, Howells GA, LuCAS RJ, et al. Nonoperative management of the adult ruptured spleen. Arch Surg 1990; 125(7): $836-8$.

12. FILLER RM. Experience with the management of splenic injuries. Aust NZ J Surg 1984; 54(5): 443-5.

13. JOSEPH TP, WYLlIE GG, SAVAGE JP. The Non-operative management of splenic trauma. Aust NZ J Surg 1977; 47(2): 179-82.

14. Lannergren K, Tordai P, Linne T, Persson U. Avoiding splenectomy in the treatment of children with splenic injury. Acta Chir Scand 1990; 156(5): 359-65.

15. AZMY AF, MacKenzIE R. Conservative management of the injured spleen in children. Scott Med J 1986; 31(3): 162-5.

16. Healy MA, Simons RK, Winchell RJ, et al. A prospective evaluation of abdominal ultrasound in blunt trauma: is it useful? J Trauma 1996; 40(6): 875-85.

17. MCKenNEDY MG, MARTIN L, LentZ K, et al. 1,000 consecutive ultrasounds for blunt abdominal trauma. $J$ Trauma 1996; 40(4): 607-612.

18. Guth AA, PACHTER HL, JACOBOwITZ GR. Rupture of the pathologic spleen: is there a role for nonoperative therapy? $J$
Trauma 1996; 41(2): 214-8.

19. Fort DW, Bernini JC, Johnson A, Cochran CJ, Buchanan GR. Splenic rupture in haemophilia. Am J Pediatr Hematol Oncol 1994; 16(3): 255-9.

20. LUNA GK, DELLINGER EP. nonoperative observation therapy MA,

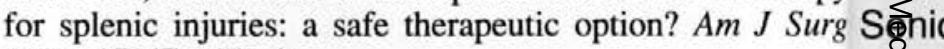
1987; 153(5): 462-8.

21. Wasvary H, Howells G, Villalba M, et al. Nonoperative $N$ Offfie management of adult blunt splenic trauma: a 15-year experience. Am Surg 1997; 63(8): 694-9.

22. MORGENSTERN L. UYEDA RY. Nonoperative management of injuries of the spleen in adults. Surg Gynecol Obstet 1983; 157(6): 513-18.

23. Petroianu A, da Silva RG, Simal CJ, de Carvalho DG, da $M \overline{\widehat{D}} H$ SILVA RA. Late postoperative follow-up of patients submitted to subtotal splenectomy. Am Surg 1997; 63(8): 735-40.

24. Chung SW, Nagy AG. Preservation of the spleen using human fibrin seal. Can J Surg 1988; 31(3): 195-7.

25. Lange DA, Zaret P, Merlotti GJ, Robin AP, SheafF C, BARRETT JA. The use of absorbably mesh in splenic trauma. J Trauma 1988; 28(3): 269-75.

26. Rizk N, Champault G, Boutelier P. Laparoscopic splenic SI仓़M salvage in blunt abdominal trauma. Acta Chir Belg 1995; 95(4 suppl): 202-4.

27. Greco RS, Alvarez FG. Protection against pneumococcal bacteraemia by partial splenectomy. Surg Gynecol Obstet 1981; 152: 67-9.

28. Tzoracoleftherakis E, Alivizatos V, Kalfarentzos F, ANDROUlaKIS J. Complications of splenic tissue reimplantation. Ann R Coll Surg Engl 1991; 73(2): 83-6.

29. Pitcher ME, Cade RJ, Mackay JR. Splenectomy for trauma: morbidity, mortality and associated abdominal injuries. Aust NZ J Surg 1989; 59(6): 461-3.

30. Wiebke EA, Sarr MG, Fishman EK, Ratych RE. Nonoperative management of splenic injuries in adults: an alternative in selected patients. Am Surg 1987; 53(10): 54752. 